\title{
Super Water-Retainer Hydrogels: Crosslinked Acrylamide/Succinic Acid Copolymers
}

\author{
Dursun Saraydin, ${ }^{\dagger}$ Erdener KaradaĞ, and Olgun Güven* $^{*}$ \\ Department of Chemistry, Cumhuriyet University, 58140 Sivas-Turkey \\ * Department of Chemistry, Hacettepe University, Beytepe, 06532 Ankara-Turkey
}

(Received July 15, 1996)

\begin{abstract}
Super water-retainer hydrogels in the rod form were prepared by copolymerization of acrylamide and succinic acid monomers with $\gamma$ radiation. Swelling took place in water at $25^{\circ} \mathrm{C}$ and was followed by weighing. The influence of dose and relative content of succinic acid on the swelling properties, diffusional behavior of water, diffusion coefficients and network properties of hydrogel systems were examined. Acrylamide/succinic acid hydrogels were swollen in the range of $750-960 \%$, while polyacrylamide hydrogels at $650-700 \%$. Water diffusion into hydrogels was non-Fickian type diffusion. Diffusion coefficients of acrylamide/succinic acid hydrogels were calculated by the short time approximation as $4.6 \times$ $10^{-7}-7.9 \times 10^{-7} \mathrm{~cm}^{2} \mathrm{~s}^{-1}$

KEY WORDS Acrylamide-Succinic Acid / Hydrogel / Swelling /
\end{abstract}

Hydrogels are interesting and have both liquid-like and solid-like properties. ${ }^{1-10}$ The liquid-like properties result from the fact that the major constituent of gels is usually a liquid, e.g., water. A hydrogel can be viewed as a container of water made of a three-dimensional mesh. In a dried state, a gel is a solid material. However, a hydrogel swells until it reaches the swelling equilibrium when water is added. Water molecules are kept in the three-dimensional mesh and the combination of mesh and water molecules creates a "world" having characteristic properties. This world can be either isolated from (isochore) or linked to (isobar) its surrounding world by changing the population, i.e., water molecules. ${ }^{4}$ Hydrogels have widespread applications in the bioengineering, biomedicine, pharmaceutical, food industry, veterinary, agricultural, environmental and related fields. ${ }^{11-15}$

Polyacrylamide (PAAm) hydrogels and derivatives are used much. PAAm hydrogels have capability of water absorption and biocompatibility with physiologic body fluids. ${ }^{16-20}$

In our previous study, acrylamide based hydrogels such as acrylamide/crotonic acid, ${ }^{21}$ acrylamide/maleic acid, ${ }^{22}$ acrylamide/itaconic acid, ${ }^{23}$ and acrylamide/tartaric acid ${ }^{24}$ were prepared and used in adsorptions of some heavy metal ions, ${ }^{25}$ uranyl ions, ${ }^{26}$ basic dyes, ${ }^{27-30}$ bovine serum albumin, ${ }^{19,31}$ and biocompatibility studies. ${ }^{20,32}$ Increasing water absorption capability of AAm hydrogels with the addition of succinic acid containing hydrophilic groups is purposed. Here aqueous solutions of acrylamide and succinic acid were irradiated under $\gamma$-rays at various doses. Swelling properties, diffusional parameters and network properties of hydrogels were studied.

\section{EXPERIMENTAL}

For preparation of super water-retainer hydrogel systems, acrylamide (AAm) (B.D.H., Poole-UK) weighing $1 \mathrm{~g}$ was dissolved in $1 \mathrm{~mL}$ aqueous solutions of 0,20 , 40, and $60 \mathrm{mg}$ succinic acid (SA) (B.D.H., Poole-UK).

\footnotetext{
+ To whom all correspondence should be addressed.
}

The solutions were placed in PVC straws of $4 \mathrm{~mm}$ diameter and irradiated at 2.60, 3.73, 4.65, 5.20, and $5.71 \mathrm{kGy}$ in air at ambient temperature in a ${ }^{60} \mathrm{Co}$ Gammacell 220 type $\gamma$ irradiator at a fixed dose rate of $0.72 \mathrm{kGy} \mathrm{h}^{-1}$. The dose rate was determined by the conventional Fricke dosimeter. Fresh hydrogels obtained in long cylindrical shapes were cut into pieces of $3-4 \mathrm{~mm}$ in length. They were washed and thoroughly rinsed with distilled water, blot dried with filter paper, dried in air and vacuum, and stored for swelling studies.

Dried crosslinked copolymers were accurately weighed and transferred into water. Water uptake with respect to time was obtained by periodically removing a sample from water, quickly blot drying, and reweighing. The measurements were conducted at $25 \pm 0.1^{\circ} \mathrm{C}$ in a water bath.

\section{RESULTS AND DISCUSSION}

A radiation technique seems promising for preparation of hydrogels because a polymer in aqueous solution or water-swollen state readily undergoes crosslinking on irradiation to yield a gel-like material. Since this hydrogel is not contaminated with foreign additives and crosslink must be composed of stable $\mathrm{C}-\mathrm{C}$ bonds, it is of interest to study the preparation of hydrogels by irradiation. ${ }^{16,17}$

\section{Preparation}

Ionizing radiation was used for preparation of AAm and AAm/SA copolymers. When monomers of AAm and SA are irradiated with ionization rays such as $\gamma$ rays, one double bond of $-\mathrm{C}=\mathrm{C}-$ on $\mathrm{AAm}$ and one or two of $\mathrm{C}-\mathrm{H}$ bonds of SA were broken by ionization irradiation and free radicals are generated. These free radicals react with each other, and a copolymer of $\mathrm{AAm} / \mathrm{SA}$ is produced. A possible free radical polymerization reaction of poly(AAm/SA) by $\gamma$ rays irradiation is shown in Scheme 1. When irradiation dose is increased during ionizing radiation of $\mathrm{AAm}, \mathrm{SA}$, and water ternary mixtures, the polymer chains crosslink and gel is obtained. Oxygen does not affect the polymerization of AAm. ${ }^{33} \mathrm{It}$ is reported that complete gelation of AAm is $2.00 \mathrm{kGy}$ 


$$
\begin{aligned}
& \mathrm{H}_{2} \mathrm{O} \stackrel{\gamma \text {-rays }}{\longrightarrow} \mathrm{R} \cdot(\mathrm{H} \cdot, \mathrm{HO} \cdot, \text { etc., })
\end{aligned}
$$

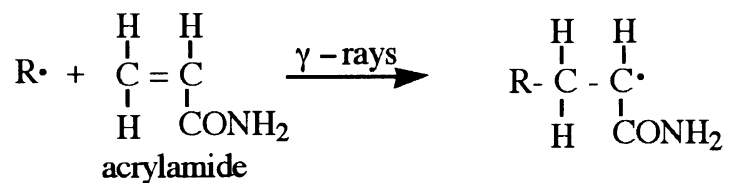

radical formation

initiation

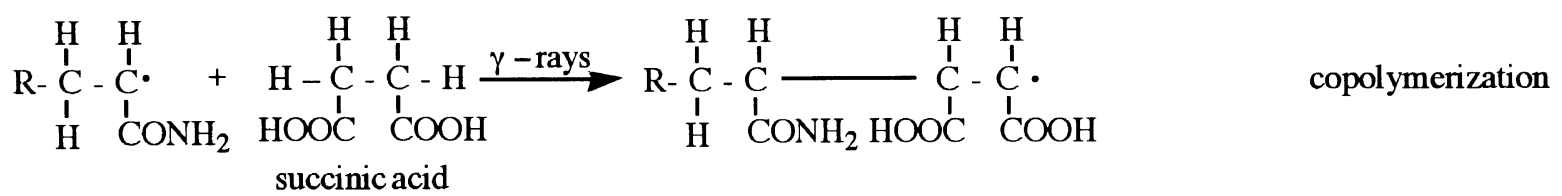

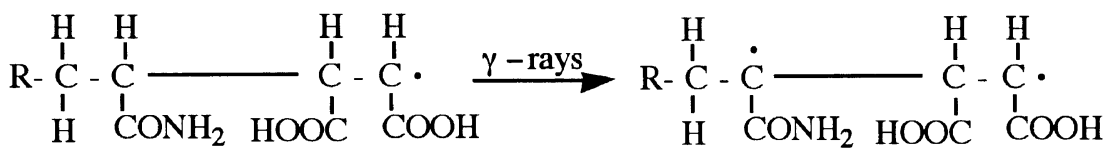

macroradical formation

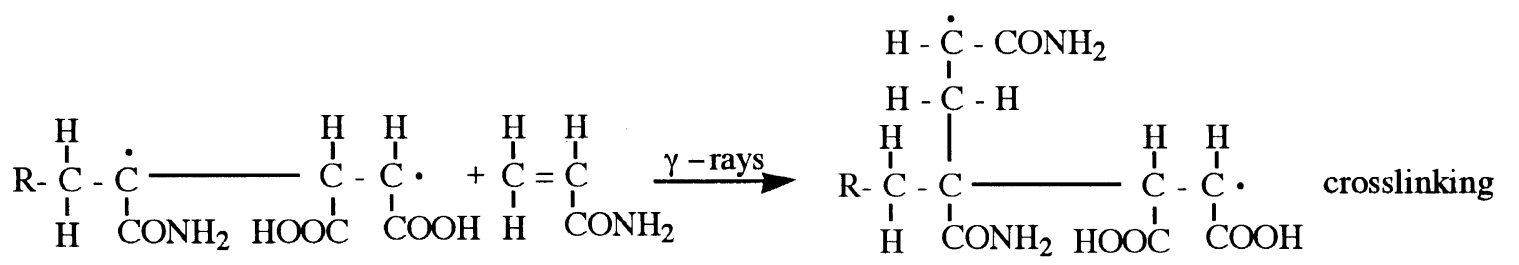

Scheme 1. Possible copolymerization and crosslinking mechanisms of acrylamide and succinic acid.

of $\gamma$ rays irradiation doses at ambient temperature. ${ }^{34}$ So, a dose of $2.60 \mathrm{kGy}$ of $\gamma$ rays is used for preparation of AAm/SA hydrogels.

Dried AAm/SA copolymers are glassy form and very hard, but swollen gels are very soft. The crosslinked copolymers are obtained in the form of cylinders. Upon swelling the hydrogels retain their shape.

\section{Swelling}

A fundamental relationship exists between the swelling of a polymer in a solvent and the nature of the polymer and the solvent. ${ }^{35,36}$ The mass swelling $[\% S(m)]$ of the super water-retainer hydrogels in distilled water was calculated from the following relation ${ }^{35}$

$$
\% S(m)=\frac{m_{\mathrm{t}}-m_{0}}{m_{0}} \times 100
$$

where $m_{\mathrm{t}}$ is the mass of the swollen gel at time $t$ and $m_{0}$ is the mass of the dry gel at time 0 .

The water intake of initially dry hydrogels was followed for a long time. Swelling curves of the hydrogels are plotted and representative swelling curves are shown in Figures 1 and 2.

Figures 1 and 2 show that swelling is increased by time, but after some time, it shows constant swelling. This value of swelling may be named mass equilibrium swelling (MES). MES of AAm/SA copolymers are used for the calculation of some network characterization parameters. MES of AAm/SA copolymers are given Table I.

To determine the volumetric equilibrium swelling (VES), it is necessary to place a sample of known density in the chosen solvent until mass measurements indicate

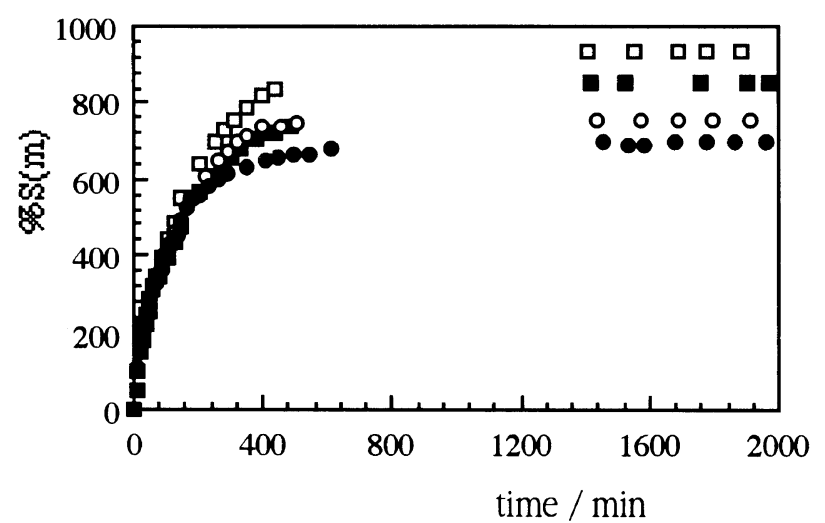

Figure 1. Combined effects of water and succinic acid on the swelling of AAm/SA copolymers. Total dose given $5.2 \mathrm{kGy}$. - - $0 \mathrm{mg} \mathrm{SA}$; -,$- 20 \mathrm{mg} \mathrm{SA} ;-\square-, 40 \mathrm{mg} \mathrm{SA} ;-\square-, 60 \mathrm{mg} \mathrm{SA}$.

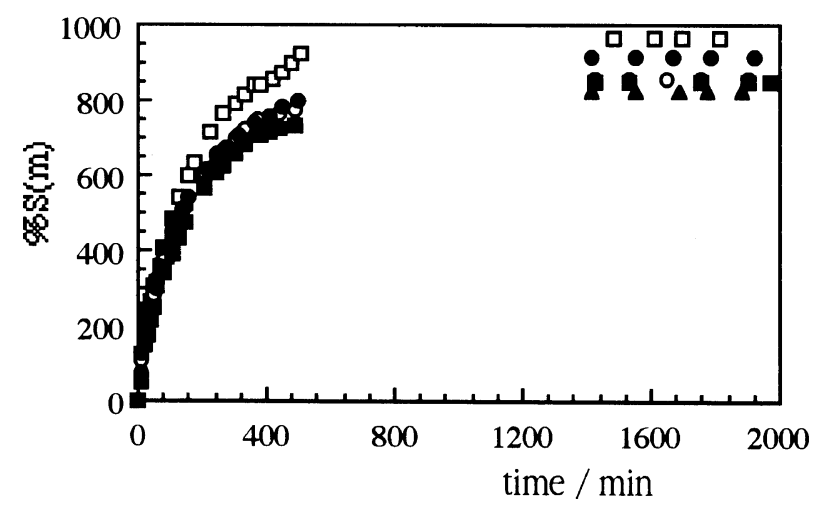

Figure 2. Combined effects of water and irradiation dose on the swelling of AAm/SA copolymers containing $40 \mathrm{mg}$ succinic acid. $-\square-$
$5.20 \mathrm{kGy} ;-\mathbf{\Delta -}-5.71 \mathrm{kGy}$. 
Table I. Variation of MES and VES of AAm/SA hydrogels with SA content and irradiation dose

\begin{tabular}{|c|c|c|c|c|c|c|c|c|c|c|}
\hline \multirow{2}{*}{$\begin{array}{l}\text { Dose } \\
\text { SA }\end{array}$} & \multicolumn{2}{|c|}{$2.60 \mathrm{kGy}$} & \multicolumn{2}{|c|}{$3.73 \mathrm{kGy}$} & \multicolumn{2}{|c|}{$4.65 \mathrm{kGy}$} & \multicolumn{2}{|c|}{$5.20 \mathrm{kGy}$} & \multicolumn{2}{|c|}{$5.71 \mathrm{kGy}$} \\
\hline & MES & VES & MES & VES & MES & VES & MES & VES & MES & VES \\
\hline $0 \mathrm{mg}$ & 685 & 895 & 665 & 865 & 675 & 880 & 695 & 910 & 695 & 910 \\
\hline $20 \mathrm{mg}$ & 875 & 1140 & 855 & 1120 & 825 & 1080 & 755 & 985 & 755 & 990 \\
\hline $40 \mathrm{mg}$ & 965 & 1260 & 915 & 1200 & 860 & 1125 & 855 & 1115 & 825 & 1080 \\
\hline $60 \mathrm{mg}$ & 965 & 1260 & 940 & 1230 & 950 & 1240 & 935 & 1220 & 850 & 1110 \\
\hline
\end{tabular}

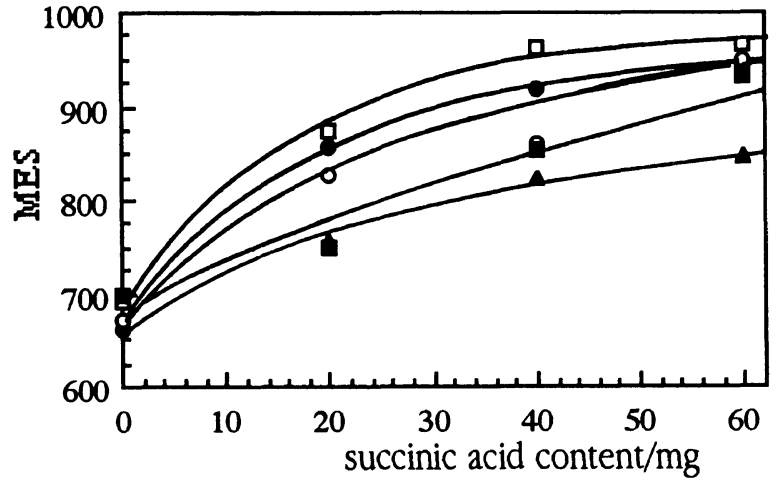

Figure 3. Variation of MES of AAm/SA copolymers with SA content in hydrogels. $-\square-, 2.60 \mathrm{kGy} ;-\longrightarrow-3.73 \mathrm{kGy} ;-\bigcirc-, 4.65 \mathrm{kGy}$; 一- $5.20 \mathrm{kGy} ;-\mathbf{\Delta}-, 5.71 \mathrm{kGy}$.

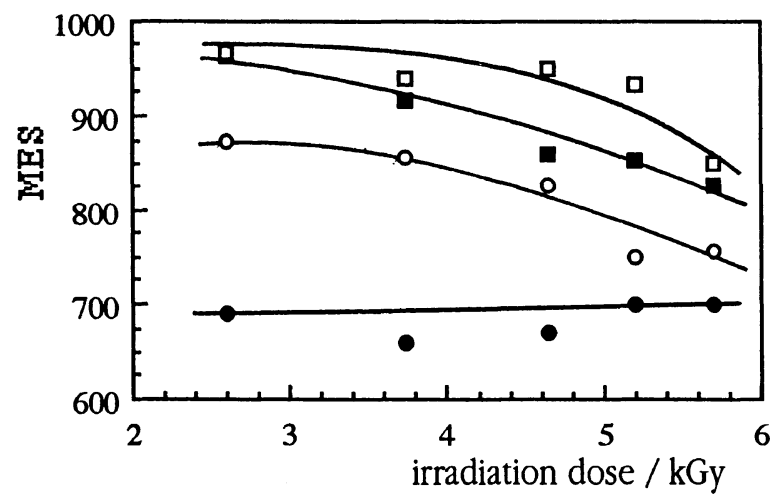

Figure 4. Variation of MES of AAm/SA copolymers with the irradiation dose. - -, $0 \mathrm{mg} \mathrm{SA}$; —,$- 20 \mathrm{mg} \mathrm{SA} ;-\mathbf{\square -}, 40 \mathrm{mg}$ $\mathrm{SA} ;-\square-, 60 \mathrm{mg} \mathrm{SA}$.

the cessation of uptake of liquid by the polymer. If nothing is extractable and if all imbibed solvent causes swelling, Volumetric swelling; $\% S(v)$, is given by

$$
\% S(V)=\frac{\left(m_{\mathrm{t}}-m_{0}\right) d_{\mathrm{p}}}{m_{0} d_{\mathrm{s}}} \times 100
$$

where $d_{\mathrm{s}}$ and $d_{\mathrm{p}}$ are the water density and polymer density, respectively. ${ }^{37} m_{0}$ and $m_{\mathrm{t}}$ were defined earlier.

VES of AAm/SA hydrogels is given in Table I.

Table I shows that MES of AAm are $650-700 \%$, but MES of AAm/SA super water-retainer hydrogels are $750-960 \%$. VES are varied similarly as the results of MES. VES of AAm/SA super water-retainer hydrogels are varied at $1000-1260 \%$. Hydrophilic groups of AAm/SA copolymers are greater than those of AAm, so, the swelling of AAm/SA copolymers is greater than swelling of AAm hydrogels.

For understanding the effect of the content of SA in the super water-retainer hydrogels and $\gamma$ rays dose, MES

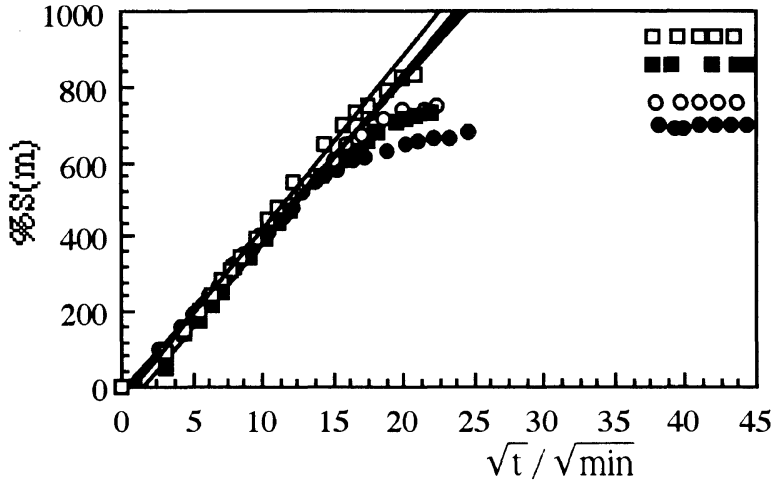

Figure 5. Plots of swelling rate for AAm/SA copolymers. Total dose given $5.20 \mathrm{kGy}$. - - $-0 \mathrm{mg} \mathrm{SA} ;-\mathrm{O}_{-}, 20 \mathrm{mg} \mathrm{SA} ;-\square-, 40 \mathrm{mg} \mathrm{SA}$; $-\square-, 60 \mathrm{mg} \mathrm{SA}$.

Table II. Variation of the swelling rate constant $\left(k_{\mathrm{s}}\right)$ of AAm/SA hydrogels with SA content and irradiation dose

\begin{tabular}{rccccc}
\hline SA & $2.60 \mathrm{kGy}$ & $3.73 \mathrm{kGy}$ & $4.65 \mathrm{kGy}$ & $5.20 \mathrm{kGy}$ & $5.71 \mathrm{kGy}$ \\
\hline $0 \mathrm{mg}$ & 39.43 & 37.55 & 40.74 & 41.31 & 40.60 \\
$20 \mathrm{mg}$ & 46.11 & 60.03 & 49.60 & 44.94 & 41.70 \\
$40 \mathrm{mg}$ & 50.58 & 47.17 & 49.98 & 46.98 & 46.24 \\
$60 \mathrm{mg}$ & 49.62 & 49.33 & 49.99 & 49.15 & 46.45 \\
\hline
\end{tabular}

of the hydrogels versus the content of SA and $\gamma$ rays dose are plotted in Figures 3 and 4.

In Figures 3 and 4, MES of the super water-retainer hydrogels is decreased with increase of irradiation dose and, increased with the SA content in the copolymers. MES of AAm/SA hydrogels is higher than MES of AAm hydrogels. The reason of this is the hydrophilic groups on the SA. The more the hydrophilic groups on the SA, the more swelling on the AAm/SA hydrogels.

If $\gamma$ ray dose increases during ionizing radiation of AAm, SA, and water ternary mixtures, the number of the small chains increases at unit copolymerization time, and the crosslink density of the hydrogels is higher than the lower $\gamma$ ray doses, and at the same time, the number-average molar mass of the polymer between crosslinks, is smaller than the lower $\gamma$ ray dose.

For examination of swelling characteristic of AAm/SA super water-retainer hydrogels, other important parameter is swelling rate coefficient. This parameter is about swelling ability of hydrogel system. To determine the swelling rate coefficient, swelling vs. the square root of immersion time was plotted, and representative curves are shown in Figure 5. Swelling rate coefficients were calculated from the slopes of the straight portion of the curves $^{38}$ in Figure 5, and are tabulated in Table II.

Table II shows that the similar results and identical 
behavior of swelling of AAm/SA hydrogels with the changing content of SA and irradiation dose.

\section{Diffusion}

When a glassy hydrogel is brought into contact with water, water diffuses into the hydrogel and the hydrogel swells. Diffusion involves migration of water into preexisting or dynamically formed spaces between hydrogel chains. Swelling of the hydrogel involves larger segmental motion resulting, ultimately, in increased separation between hydrogel chains. ${ }^{39-44}$

Analysis of the mechanisms of water diffusion in swellable polymeric systems has received considerable attention in recent years, because of important applications of swellable polymers in biomedical, pharmaceutical, environmental, and agricultural engineering. ${ }^{45-49}$

The following equations are used to determine the nature of diffusion of water into hydrogels.

$$
F=k t^{n}
$$

where $F$ is the fractional uptake at time $t . k$ is a constant incorporating characteristic of the macromolecular network system and the penetrant and $n$ is the diffusional exponent, which is indicative of the transport mechanism. Equation 3 is valid for the first $60 \%$ of the fractional uptake. Fickian diffusion and Case II transport are defined by $n$ equal to $1 / 2$ and $n$ equal to 1 , respectively. Anomalous transport behavior (non-Fickian diffusion) is intermediate between Fickian and Case II. This is reflected by anomalous behavior defined by values of $n$ between $1 / 2$ and $1 .{ }^{50}$

For super water-retainer hydrogels, $\ln F v s . \ln t$ graphs is plotted and representative results are shown in Figure 6. $n$ exponents and $k$ parameters are calculated from the slopes and intercepts of the lines, respectively, and are listed in Table III.

Table III shows the number determining type of diffusion $(n)$ is over 0.50 . Hence the diffusion of water into the super water-retainer hydrogels is generally taken as a non-Fickian character. ${ }^{50}$ When diffusion type is anomalous behavior, the relaxation and diffusion time are of the same order of magnitude. As the solvent diffuses into the hydrogel, rearrangement of chains does not occur immediately.
The study of diffusion phenomena in hydrogels and water is of value in that it clarifies polymer behavior. ${ }^{51}$ For hydrogel characterization, diffusion coefficient can be calculated by various methods. ${ }^{51-55}$ The short time approximation method is used for calculation of diffusion coefficients of AAm/SA hydrogels. ${ }^{52}$ The short time approximation is valid for the first $60 \%$ of swelling.

The diffusion coefficients of the cylindirical AAm/SA hydrogels are calculated from the following relations:

$$
F=4\left[\frac{D t}{\pi r^{2}}\right]^{1 / 2}-\pi\left[\frac{D t}{\pi r^{2}}\right]-\frac{\pi}{3}\left[\frac{D t}{\pi r^{2}}\right]^{3 / 2}+\cdots
$$

Where $D$ in $\mathrm{cm}^{2} \mathrm{~s}^{-1}, t$ in second and $r$ is the radius of cylindrical polymer sample. A graphical comparation of eq 3 and 4 shows the semi-empirical eq 3 with $n=0.5$ $k=4\left(D / \pi r^{2}\right)^{1 / 2}$.

For hydrogels, $F$ versus $t^{1 / 2}$ plots is plotted and representative results are shown in Figure 6. The diffusion coefficients were calculated from the slope of the lines. The values of diffusion coefficient determined for the super water-retainer hydrogels are listed in Table IV.

Table IV shows that the values of the diffusion coefficient of the AAm/SA hydrogels vary from $4.6 \times$ $10^{-7} \mathrm{~cm}^{2} \mathrm{~s}^{-1}$ to $7.9 \times 10^{-7} \mathrm{~cm}^{2} \mathrm{~s}^{-1}$.

\section{Network Studies}

One important structural parameter characterizing

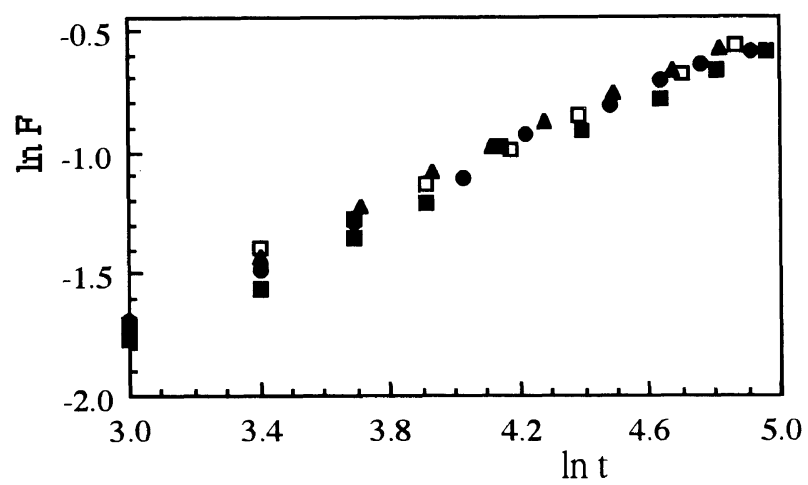

Figure 6. Plots of $\ln F$ vs. $\ln t$ for AAm/SA copolymers containing $40 \mathrm{mg}$ SA. $-\square-, 2.60 \mathrm{kGy} ;-\bigcirc-, 3.73 \mathrm{kGy}$; $-\square-, 5.20 \mathrm{kGy}$; $-\mathbf{\Delta - ,}, 5.71 \mathrm{kGy}$.

\begin{tabular}{|c|c|c|c|c|c|c|c|c|c|c|}
\hline \multirow{2}{*}{$\begin{array}{c}\text { Dose } \\
\text { SA }\end{array}$} & \multicolumn{2}{|c|}{$2.60 \mathrm{kGy}$} & \multicolumn{2}{|c|}{$3.73 \mathrm{kGy}$} & \multicolumn{2}{|c|}{$4.65 \mathrm{kGy}$} & \multicolumn{2}{|c|}{$5.20 \mathrm{kGy}$} & \multicolumn{2}{|c|}{$5.71 \mathrm{kGy}$} \\
\hline & $k \times 10^{2}$ & $n$ & $k \times 10^{2}$ & $n$ & $k \times 10^{2}$ & $n$ & $k \times 10^{2}$ & $n$ & $k \times 10^{2}$ & $n$ \\
\hline $20 \mathrm{mg}$ & 3.30 & 0.58 & 2.54 & 0.64 & 4.35 & 0.56 & 3.45 & 0.60 & 3.37 & 0.60 \\
\hline $40 \mathrm{mg}$ & 3.35 & 0.58 & 3.54 & 0.56 & 3.10 & 0.60 & 2.72 & 0.61 & 2.71 & 0.64 \\
\hline $60 \mathrm{mg}$ & 4.80 & 0.51 & 3.30 & 0.58 & 3.64 & 0.57 & 2.35 & 0.65 & 2.52 & 0.65 \\
\hline
\end{tabular}

Table III. Variation of $n$ and $k$ of AAm/SA hydrogels with SA content and irradiation dose

\begin{tabular}{|c|c|c|c|c|c|}
\hline SA & $2.60 \mathrm{kGy}$ & $3.73 \mathrm{kGy}$ & $4.65 \mathrm{kGy}$ & $5.20 \mathrm{kGy}$ & $5.71 \mathrm{kGy}$ \\
\hline $0 \mathrm{mg}$ & $8.0 \times 10^{-7}$ & $8.9 \times 10^{-7}$ & $10.0 \times 10^{-7}$ & $9.0 \times 10^{-7}$ & $9.6 \times 10^{-7}$ \\
\hline $20 \mathrm{mg}$ & $5.8 \times 10^{-7}$ & $5.0 \times 10^{-7}$ & $6.6 \times 10^{-7}$ & $6.9 \times 10^{-7}$ & $6.2 \times 10^{-7}$ \\
\hline $40 \mathrm{mg}$ & $5.3 \times 10^{-7}$ & $5.8 \times 10^{-7}$ & $6.1 \times 10^{-7}$ & $4.6 \times 10^{-7}$ & $6.6 \times 10^{-7}$ \\
\hline $60 \mathrm{mg}$ & $7.9 \times 10^{-7}$ & $7.2 \times 10^{-7}$ & $7.0 \times 10^{-7}$ & $5.3 \times 10^{-7}$ & $7.0 \times 10^{-7}$ \\
\hline
\end{tabular}

Table IV. Variation of the diffusion coefficient $\left(\mathrm{D} \mathrm{cm}^{-2} \mathrm{~s}^{-1}\right)$ of AAm/SA hydrogels with SA content and irradiation dose 
crosslinked polymers is $M_{\mathrm{c}}$, the average molar mass between crosslinks directly related to the crosslink density. The magnitude of $M_{\mathrm{c}}$ significantly affects the physical and mechanical properties of crosslinked polymers and its determination has great practical significance. Equilibrium swelling is widely used to determine $M_{\mathrm{c}}$. Early research by Flory and Rehner laid the foundations for analysis of equilibrium swelling. According to the theory of Flory and Rehner, for a network

$$
M_{\mathrm{c}}=-V_{1} d_{\mathrm{p}} \frac{v_{\mathrm{s}}^{1 / 3}-v_{\mathrm{s}} / 2}{\ln \left(1-v_{\mathrm{s}}\right)+v_{\mathrm{s}}+\chi v_{\mathrm{s}}^{2}}
$$

where $V_{1}$ is the molar volume $\left(\mathrm{mL} \mathrm{mol}^{-1}\right), d_{\mathrm{p}}$ is the polymer density $\left(\mathrm{g} \mathrm{mL}^{-1}\right), v_{\mathrm{s}}$ is the volume fraction of polymer in the swollen gel, $\chi$; is the Flory-Huggins interaction parameter between solvent and polymer. ${ }^{56}$

The swelling ratio $(Q)$ is equal to $1 / v_{\mathrm{s}}$. Here, the crosslink density, $q$, is defined as the mol fraction of crosslinked units. ${ }^{56}$

$$
q=M_{\mathrm{o}} / M_{\mathrm{c}}
$$

where, $M_{0}$ is the molar mass of the repeating unit.

Other authors define a crosslink density, $v_{\mathrm{e}}$, as the number of elastically effective chains, totally included in a network, per unit volume. $v_{\mathrm{e}}$ is simply related to $q$ since

$$
v_{\mathrm{e}}=d_{\mathrm{p}} N_{\mathrm{A}} / M_{\mathrm{c}}
$$

where $N_{\mathrm{A}}$ is Avogadro number.

Since hydrogel is copolymeric structure, the molar mass of the polymer repeat unit, $M_{0}$, can be calculated following equation,

$$
M_{0}=\frac{n_{\mathrm{AAm}} \times M_{\mathrm{AAm}}+n_{\mathrm{SA}} \times M_{\mathrm{SA}}}{n_{\mathrm{AAm}}+n_{\mathrm{SA}}}
$$

where $n_{\mathrm{AAm}}$ and $n_{\mathrm{SA}}$ are the mol number of AAm and SA (mol) and, $M_{\mathrm{AAm}}$ and $M_{\mathrm{SA}}$ are the molar mass of AAm and SA $\left(\mathrm{g} \mathrm{mol}^{-1}\right)$, respectively.

$V_{1}, d_{\mathrm{p}}$, and $\chi$ were taken from related literature. ${ }^{16,57,58}$ $M_{\mathrm{c}}, q$, and $v_{\mathrm{e}}$ of AAm and AAm/SA hydrogels are calculated and listed in Tables $\mathrm{V}$ and VI.

Table V. Variation of number-average molar mass between crosslinks $\left(M_{\mathrm{c}}\right)$ in AAm/SA hydrogels with SA content and irradiation dose

\begin{tabular}{rccccc}
\hline SA & $2.60 \mathrm{kGy}$ & $3.73 \mathrm{kGy}$ & $4.65 \mathrm{kGy}$ & $5.20 \mathrm{kGy}$ & $5.71 \mathrm{kGy}$ \\
\hline $0 \mathrm{mg}$ & 17900 & 16300 & 17000 & 18600 & 18600 \\
$20 \mathrm{mg}$ & 34500 & 32800 & 29800 & 23300 & 23400 \\
$40 \mathrm{mg}$ & 45000 & 39500 & 33600 & 32400 & 29700 \\
$60 \mathrm{mg}$ & 45100 & 42300 & 43300 & 41200 & 32100 \\
\hline
\end{tabular}

Table $\mathrm{V}$ shows that the number-average molar mass between crosslinks of hydrogels increases with SA content of AAm/SA hydrogels while it decreases with increasing of irradiation dose. Because the SA in hydrogels includes many hydrophilic groups, AAm/SA hydrogels can swell much. Crosslink density and the number of elastically effective chains are inverse due to the value of the number-average molar mass between crosslinks (Table VI).

An other important parameter of networks is gel pore size or mesh size $(\xi) .{ }^{59}$ For determining this parameter, the end-to-end distance in the freely jointed state is determined as

$$
\bar{r}_{\mathrm{f}}=l \sqrt{N}
$$

where $l=1.54 \AA$ and the number of links, $N=\lambda M_{\mathrm{c}} / M_{0}$ and $\lambda=2$. The end-to-end distance in the unperturbed state is calculated through the characteristic ratio $C_{n}=10$

$$
\bar{r}_{0}^{2}=C_{\mathrm{n}} \bar{r}_{\mathrm{f}}^{2}
$$

The end-to-end distance in the swollen state, equivalent to the mesh size, $\xi$, is

$$
\xi=v_{\mathrm{s}}^{-1 / 3} r_{0}
$$

The values of number of repeating units between crosslinks, $N$ and the mesh size, $\xi(\AA)$, are shown in Table VII.

Table VII is shown similar results and identical behavior of $M_{\mathrm{c}}$ of AAm/SA hydrogels with changing content of SA and irradiation dose.

\section{CONCLUSION}

For AAm/SA super water-retainer hydrogels, favorable SA contents are in the range of $20-60 \mathrm{mg} \mathrm{SA}$ and

\begin{tabular}{|c|c|c|c|c|c|c|c|c|c|c|}
\hline \multirow{2}{*}{$\begin{array}{c}\text { Dose } \\
\text { SA }\end{array}$} & \multicolumn{2}{|c|}{$2.60 \mathrm{kGy}$} & \multicolumn{2}{|c|}{$3.73 \mathrm{kGy}$} & \multicolumn{2}{|c|}{$4.65 \mathrm{kGy}$} & \multicolumn{2}{|c|}{$5.20 \mathrm{kGy}$} & \multicolumn{2}{|c|}{$5.71 \mathrm{kGy}$} \\
\hline & $q \times 10^{3}$ & $v_{\mathrm{e}} \times 10^{-18}$ & $q \times 10^{3}$ & $v_{\mathrm{e}} \times 10^{-18}$ & $q \times 10^{3}$ & $v_{\mathrm{e}} \times 10^{-18}$ & $q \times 10^{3}$ & $v_{\mathrm{e}} \times 10^{-18}$ & $q \times 10^{3}$ & $v_{\mathrm{e}} \times 10^{-18}$ \\
\hline $0 \mathrm{mg}$ & 3.97 & 43.76 & 4.34 & 47.87 & 4.17 & 46.01 & 3.80 & 41.93 & 3.82 & 42.12 \\
\hline $20 \mathrm{mg}$ & 2.08 & 22.69 & 2.19 & 23.91 & 2.40 & 26.29 & 3.07 & 33.62 & 3.06 & 33.45 \\
\hline $40 \mathrm{mg}$ & 1.62 & 17.43 & 1.85 & 19.85 & 2.17 & 23.55 & 2.25 & 24.19 & 2.46 & 26.39 \\
\hline $60 \mathrm{mg}$ & 1.67 & 17.36 & 1.78 & 18.54 & 1.74 & 18.10 & 1.83 & 19.02 & 2.35 & 24.43 \\
\hline
\end{tabular}
favorable irradiation, $2.60-5.71 \mathrm{kGy}$. AAm/SA copoly-

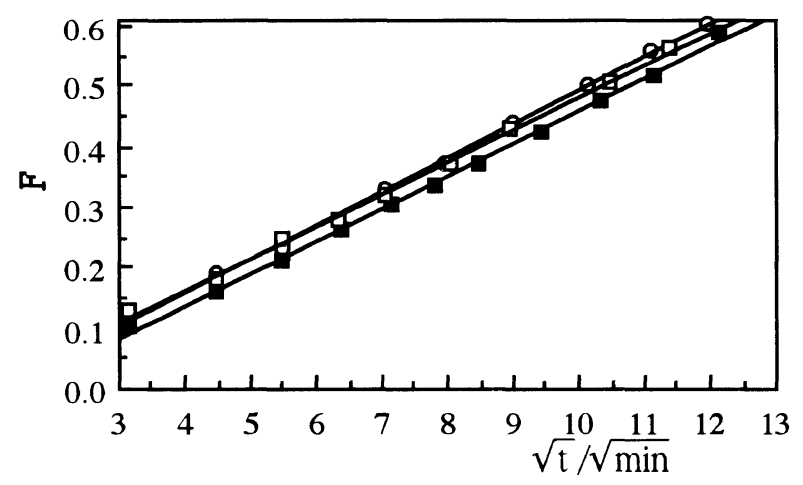

Figure 7. Plots of $F$ vs. $\sqrt{t}$ for AAm/SA copolymers containing $60 \mathrm{mg} \mathrm{SA} .-\square-, 2.60 \mathrm{kGy} ;-\mathrm{O}-, 4.65 \mathrm{kGy} ;-\square-, 5.20 \mathrm{kGy}$.

Table VI. Variation of the crosslink density $(q)$ and the number of elastically effective chains $\left(v_{\mathrm{e}}\right)$ of AAm/SA hydrogels with SA content and irradiation dose 
D. Saraydin, E. KaradaĞ, and O. Güven

Table VII. Variation of number of repeating units between crosslinks $(N)$ and mesh size $(\xi / \AA)$ of AAm/SA hydrogels with SA content and irradiation dose

\begin{tabular}{|c|c|c|c|c|c|c|c|c|c|c|}
\hline \multirow{2}{*}{$\begin{array}{c}\text { Dose } \\
\text { SA }\end{array}$} & \multicolumn{2}{|c|}{$2.60 \mathrm{kGy}$} & \multicolumn{2}{|c|}{$3.73 \mathrm{kGy}$} & \multicolumn{2}{|c|}{$4.65 \mathrm{kGy}$} & \multicolumn{2}{|c|}{$5.20 \mathrm{kGy}$} & \multicolumn{2}{|c|}{$5.71 \mathrm{kGy}$} \\
\hline & $N$ & $\xi$ & $N$ & $\xi$ & $N$ & $\xi$ & $N$ & $\xi$ & $N$ & $\xi$ \\
\hline $0 \mathrm{mg}$ & 252 & 148 & 230 & 160 & 240 & 152 & 263 & 165 & 262 & 164 \\
\hline $20 \mathrm{mg}$ & 964 & 340 & 915 & 330 & 832 & 310 & 651 & 267 & 654 & 267 \\
\hline $40 \mathrm{mg}$ & 1231 & 397 & 1081 & 336 & 921 & 331 & 887 & 332 & 813 & 307 \\
\hline $60 \mathrm{mg}$ & 1198 & 392 & 1122 & 376 & 1150 & 382 & 1094 & 371 & 851 & 317 \\
\hline
\end{tabular}

mers swelled $750-960 \%$, while polyacrylamide swelled $650-700 \%$. Water diffusion to AAm/SA hydrogels was of non-Fickian type diffusion.

The number-average molar mass between crosslinks increased with SA in the hydrogels and decreased by increasing irradiation, while crosslink density and numbers of elastically effective chains decreased by increasing SA in the hydrogels and increased with irradiation doses.

Highly swollen AAm/SA hydrogels can thus be used a super water-retainers for carrying substances in aquatic fields involving pharmaceutical, agricultural, environmental, and biomedical applications.

Acknowledgment. The authors gratefully acknowledge the support of the Polymer Group in the Department of Chemistry, Hacettepe University.

\section{REFERENCES}

1. O. Wichterle and D. Lim, Nature, 185, 117 (1960).

2. T. Tanaka, Scientific American, 224, 110 (1981).

3. Y. Osaka and S. B. Ross-Murphy, Scienfitic American, May, 42 (1993)

4. M. Shibayama and T. Tanaka, Adv. Poly. Sci., 109, 1 (1993).

5. S. A. Dubrovskii, M. V. Afanas'eva, M. A. Lagutina, and K. S. Kazanskii, Polym. Bull., 24, 107 (1990).

6. N. B. Graham and M. E. McNeill, Biomaterials, 5, 27 (1984).

7. N. A. Peppas, Poym. Prepr. Jpn., 34, 818 (1993).

8. O. Güven and M. Șen, Polymer, 32, 2491 (1991).

9. K. S. Kazanskii and S. A. Dubrowskii, Adv. Polym. Sci., 104, 97 (1992).

10. S. B. Ross-Murphy and H. McEvoy, Br. Polym. J., 18, 2 (1986).

11. G. Burillo and T. Ogawa, Radiat. Phys. Chem., 18, 1143 (1981).

12. O. Güven and M. Șen, Angew. Makromol. Chem., 207, 101 (1993).

13. W. E. Roorda, H. E. Bodda, A. G. De Boer, and H. E. Junginger, Pharm. Weekblad Sci. Ed., 8, 163 (1986).

14. A. G. Andreopoulos, J. Appl. Polym. Sci., 37, 2121 (1989).

15. J. Kost and R. Langer, "Hydrogels Medicine, and Pharmacy,"Vol. 3, N. A. Peppas, Ed., CRC Press, Florida, 1987.

16. J. Rosiak, K. Burczak, T. Czolozynska, and W. Pekala, Radiat. Chem., 22, 907 (1983)

17. J. Rosiak, K. Burczak, W. Pekala, N. Pislvski, S. Idziak, and A. Charlesby, Radiat. Phys. Chem., 32, 793 (1988).

18. K.-J. Yao and W.-J. Zhou, J. Appl. Polym. Sci., 53, 1533 (1994).

19. D. Saraydin, E. Karadağ, H. N. Öztop and Güven, Biomaterials, 15, 917 (1994)

20. D. Saraydin, E. Karadăg, S. Çetinkaya, and O. Güven, Radiat. Phys. Chem., 46, 1049 (1995).

21. D. Saraydin, E. Karadağ, and O. Güven, Tr. J. Chemistry, 19, 179 (1995).

22. D. Saraydin, E. Karadağ, and O. Güven, Polym. Adv. Technol., 6, 719 (1995).

23. E. Karadağ, D. Saraydin. and O. Güven, Colloidal. Polym. Sci., in press (1996).

24. E. Karadağ, D. Saraydin, and O. Güven, Ir. J. Polym. Sci. Technol., 4, 218 (1995).
25. D. Saraydin, E. Karadağ, and O. Güven, Sep. Sci. Technol., 30, 3291 (1995).

26. E. Karadağ, D. Saraydin, and O. Güven, Sep. Sci. Technol., 30, 3747 (1995).

27. D. Saraydin, E. Karadağ, and O. Güven, Sep. Sci. Technol., 31, 2359 (1996)

28. D. Saraydin, E. Karadăg, and O. Güven, Sep. Sci. Technol., 31, 423 (1996).

29. E. Karadağ, D. Saraydin, and O. Güven, Polym. Bull., 36, 745 (1996).

30. E. Karadağ, D. Saraydin, and O. Güven, J. Appl. Polym. Sci., 61, 2367 (1996)

31. E. Karadağ, D. Saraydin, H. N. Öztop, and O. Güven, Polym. Adv. Technol., 5, 664 (1994).

32. E. Karadağ, D. Saraydin, S. Çetinkaya, and O. Güven, Biomaterials, 17, 664 (1996).

33. N. Dole, "The radiation chemistry of macromolecules, Vol. 2, Academic Press, New York, N.Y., 1973.

34. J. Rosiak, K. Burczak, T. Czolozynska, and W. Pekala, Radiat. Phys. Chem., 22, 917 (1983).

35. N. A. Peppas and N. M. Franson, J. Polym. Sci., Polym. Phys. Ed., 21, 983 (1983).

36. H. J. Mencer and Z. Gomzi, Eur. Polym. J., 30, 33 (1994).

37. D. J. Buckley, M. Berger, and D. Poller, J. Polym. Sci., 56, 163 (1962).

38. F. Urushizaki, H. Yamaguchi, K. Nakamura, S. Numajiri, K. Sugibayashi, and Y. Morimoto, Int. J. Pharm., 58, 135 (1990).

39. A. R. Berens and H. B. Hopfenberg, Polymer, 19, 489 (1978).

40. H. L. Frisch, Polym. Eng. Sci., 20, 2 (1980).

41. L. Hagerty, J. H. Sugarman, and R. K. Prud'homme, Polymer, 29, 1058 (1988)

42. S. R. Lustig, J. M. Caruthers, and N. A. Peppas, Polym. Prepr., Jpn., 30, 7 (1989).

43. P. M. Smith and M. M. Fisher, Polymer, 25, 84 (1984).

44. K. G. Urdahl and N. A. Peppas, Polym. Eng. Sci., 28, 96 (1988).

45. M. B. Ahmad and M. B. Huglin, Polymer, 35, 1997 (1994).

46. G. Koßmehl, J. Volkheimer, and H. Schafer, Makromol. Chem., 190, 1253 (1989).

47. M. Al-Issa, T. P. Davis, M. B. Huglin, J. M. Rego, M. M. A.-M. Rehab, D. C. F. Yip, and M. B. Zakaria, Makromol. Chem., 191, 321 (1990).

48. T. P. Davis and M. B. Huglin, Makromol. Chem., 191, 331 (1990).

49. W. M. Kulicke and H. Nottelman, "Polymers in Aqueous Media, Performance through Association", Advanced in Chemistry Series, Vol. 223, J. E. Glass, Ed., The American Chemical Society, Washington, D.C., 1989, p. 15

50. P. L. Ritger and N. A. Peppas, Fuel, 66, 815 (1987).

51. D. J. Buckley and M. Berger, J. Polym. Sci., 56, 175 (1962).

52. P. L. Ritger and N. A. Peppas, J. Cont. Release, 5, 23 (1987).

53. J. Crank and G. S. Park, "Diffusion in Polymers," Academic Press, New York, N.Y., 1968.

54. V. Shankar, Polymer, 20, 254 (1979).

55. Y. Li and T. Tanaka, J. Chem. Phys., 92, 1376 (1990).

56. Z. Y. Ding, J. J. Aklonis, and R. Salovey, J. Polym. Sci., Part. B: Polym. Phys., 29, 1035 (1991).

57. M. J. Astle, "Synonim, Handbook of Chemistry and Physics," 2nd ed, C. R. Weast, Ed., CRC Press, Cleveland, 1992.

58. J. Baselga, I. Hernandez-Fuentes, R. M. Masegosa, and M. A. Llorente, Polym. J., 21, 467 (1989).

59. B. D. Barr-Howell and N. A. Peppas, J. Appl. Polym. Sci., 30, 4583 (1985) 